\title{
Effect of Crucible Materials and Oxides on Static Undercooling in Molten Nickel
}

\author{
Amir ABEDI, Masayuki KUDOH ${ }^{1)}$ and Yoichi ITOH ${ }^{11}$ \\ Graduate Student, Hokkaido University, Kita-ku, Sapporo, Hokkaido, 060 Japan. \\ 1) Graduate School of Engineering, \\ Division of Materials Science and Engineering, Hokkaido University, Kita-ku, Sapporo, Hokkaido, 060 Japan.
}

(Received on February 17, 1997; accepted in final form on April 11, 1997)

\begin{abstract}
Using fused silica and alumina crucibles, an investigation on the static undercooling behavior of nickel, with and without the addition of oxides, was conducted. The effects of the crucible materials and of the oxides on the undercooling and solidified structure were investigated.

The degree of undercooling reached $192 \mathrm{~K}$ using the fused silica crucible, and decreased to an average of $55 \mathrm{~K}$ using the alumina crucible. With the addition of alumina powder to the nickel, the lowest undercoolings were obtained. Considering a modified planar disregistry between nickel and alumina might explain why alumina acts as a good heterogeneous nucleation catalyst in molten nickel.

The addition of the alumina powder did not significantly refine the solidified structure of the specimens. The finest structures were obtained in the specimens with added $\mathrm{NiO}$ and $\mathrm{Co}_{3} \mathrm{O}_{4}$ powders which had almost no effect on the undercooling.
\end{abstract}

KEY WORDS: nickel; nucleation; heterogeneous nucleation; static undercooling; structure refinement; microstructure.

\section{Introduction}

The nucleation behavior in the solidification of metals determines many important structural features, including grain size, grain shape, phase and extent of microand macro-segregation. These structural features have a strong influence on the mechanical properties of castings, so it is important to understand and control the nucleation behavior. Many studies concerned with nucleation mechanisms and solidified structures have been reported till now. ${ }^{1-5)}$

Solidification mostly takes place by heterogeneous nucleation, because of the difficulty of removing tramp impurities from the melt. In the heterogeneous nucleation, nuclei are formed by atomic fluctuations in the melt in contact with catalysts. The tendency to undercool the melt depends strongly on the potency of the catalyst and its nucleation kinetics. ${ }^{6,7)}$ The classical theory of heterogeneous nucleation incorporates the potency of the catalyst in terms of the familiar "wetting angle" description. However, the wetting angle is only a thermodynamic definition, and it is not clear what determines this angle and how it varies with the lattice disregistry between catalyst and nucleus, the topography of the catalyst surface, the electrostatic and chemical nature of the catalyst, the adsorbed impurities on the surface of the catalyst, etc. ${ }^{8)}$ There have been several attempts to develop the theory of heterogeneous nucleation of solidification. ${ }^{9-11)}$ One of them is the disregistry theory which is supported by much experimental data.
In this study the effects on the static undercooling of nickel of fused silica and alumina crucibles and of oxides powders added to the raw material were investigated. "Static undercooling" is the large undercooling before initial nucleation in a molten metal with a low cooling rate. The static undercooling is mainly controlled by the heterogeneous nucleation catalyst.

\section{Experimental Method}

Nickel pellets with $99.97 \%$ purity were used for raw material. The total mass of raw material used in each run was $0.05 \mathrm{~kg}$. Figure 1 shows the schematic illustration of the experimental apparatus. In the first set of experiments, a fused silica crucible with a $0.02 \mathrm{~m}$ inner diameter was supported by an alumina tube. The crucible was hung in the uniform temperature region of an electrical furnace by a protective tube of the thermocouple. Temperature was monitored with a B $(6-30$ $\mathrm{Pt}-\mathrm{Rh}$ ) thermocouple which was inserted in the center of the specimen. Tests were performed under an $\mathrm{Ar}$ atmosphere. The crucible was heated to $1780 \mathrm{~K}$ and kept at that temperature for about $600 \mathrm{~s}$. The melt was then cooled by quickly withdrawing the crucible to a predetermined position in the furnace. The average cooling rate was about $1.8 \mathrm{~K} / \mathrm{s}$. The degree of undercooling was determined by subtracting the minimum temperature recorded before recalescence from the melting point of pure nickel, $1726 \mathrm{~K}$.

In order to clarify the effect of oxide additives on the 


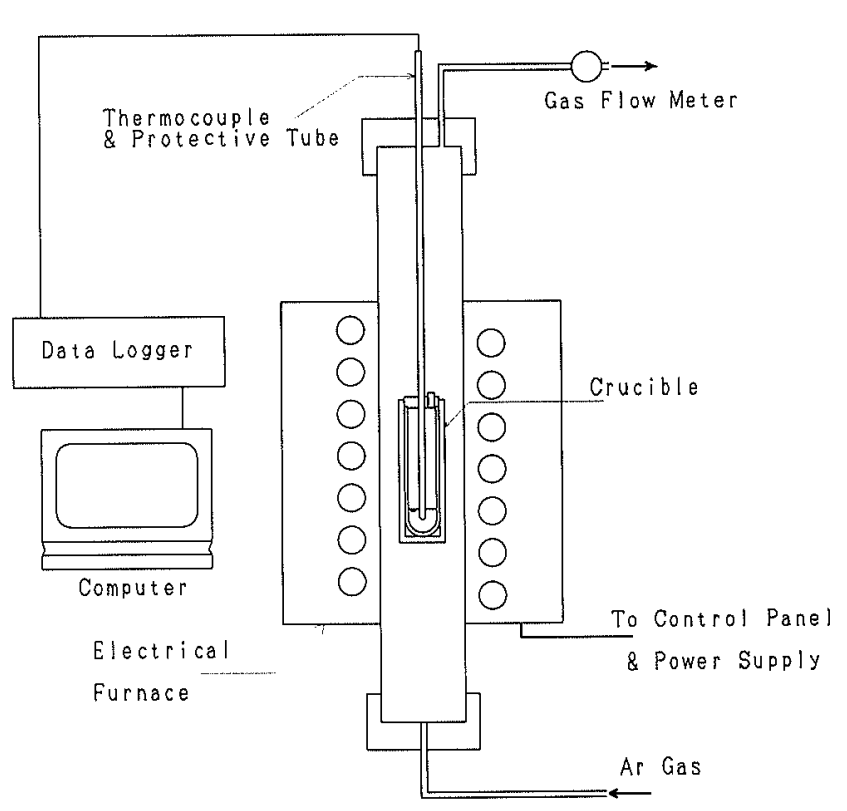

Fig. 1. Schematic diagram of the experimental apparatus.

undercooling and solidified structure, about 0.2 mass $\%$ of the oxide powders, $\mathrm{Al}_{2} \mathrm{O}_{3}, \mathrm{Co}_{3} \mathrm{O}_{4}$, and $\mathrm{NiO}$, was sandwiched within the raw material. It should be noted here that alumina is a currently used mold material and that $\mathrm{Co}_{3} \mathrm{O}_{4}$ and $\mathrm{CoAl}_{2} \mathrm{O}_{4}$ are used as refining agents in the casting of Ni-base alloys. ${ }^{12-15)}$

Furthermore, to ensure that alumina acted as heterogeneous nucleation catalyst in the molten nickel, $\mathrm{NiO}$ powder was added to a raw material of a $\mathrm{Ni}-0.15$ mass \%Al alloy in a fused silica crucible. Thus alumina was produced within the molten nickel by the reaction of $\mathrm{NiO}$ with solute aluminum.

In the other set of experiments, an alumina crucible was used. This time the supporting tube was eliminated, because the alumina crucible had enough strength. Then the heat extraction increased, and the average cooling rate was $4.7 \mathrm{~K} / \mathrm{s}$. The effects of the oxide additives, $\mathrm{Al}_{2} \mathrm{O}_{3}$, $\mathrm{Co}_{3} \mathrm{O}_{4}, \mathrm{NiO}, \mathrm{CoAl}_{2} \mathrm{O}_{4}$, and $\mathrm{NiAl}_{2} \mathrm{O}_{4}$, on the undercooling and solidified structure were then examined.

The specimens were longitudinally sectioned, polished, and etched by a $\mathrm{HNO}_{3}$ and acetic acid $1: 1$ solution to observe the microstructure. Also, X-ray Micro Analysis (XMA) and chemical analysis were performed on the specimens. X-ray diffraction and XMA were also done on some of the crucibles.

\section{Results}

\subsection{Effect of Crucible Materials on Undercooling}

Table 1 shows the effect of crucible materials on the undercooling of molten nickel without addition of oxides. Experiments were repeated several times, and the range and average of the undercoolings are listed in the Table 1. An average undercooling, $152 \mathrm{~K}$, is shown by using the fused silica crucibles, and a low undercooling, $55 \mathrm{~K}$, is shown by using the alumina crucible. The degree of undercooling in the alumina crucible is about one third of that in the fused silica crucible in spite of somewhat higher cooling rates.
Table 1. Degrees of undercooling of molten nickel in fused silica and alumina crucibles.

\begin{tabular}{lccc}
\hline Crucible material & $\begin{array}{c}\text { Range of } \\
\text { undercooling }\end{array}$ & $\begin{array}{c}\text { Av. of } \\
\text { undercooling }\end{array}$ & $\Delta T / T_{\mathrm{m}}$ \\
\hline Fused silica & $117-192 \mathrm{~K}$ & $152 \mathrm{~K}$ & 0.09 \\
Alumina & $38-78 \mathrm{~K}$ & $55 \mathrm{~K}$ & 0.03 \\
\hline
\end{tabular}
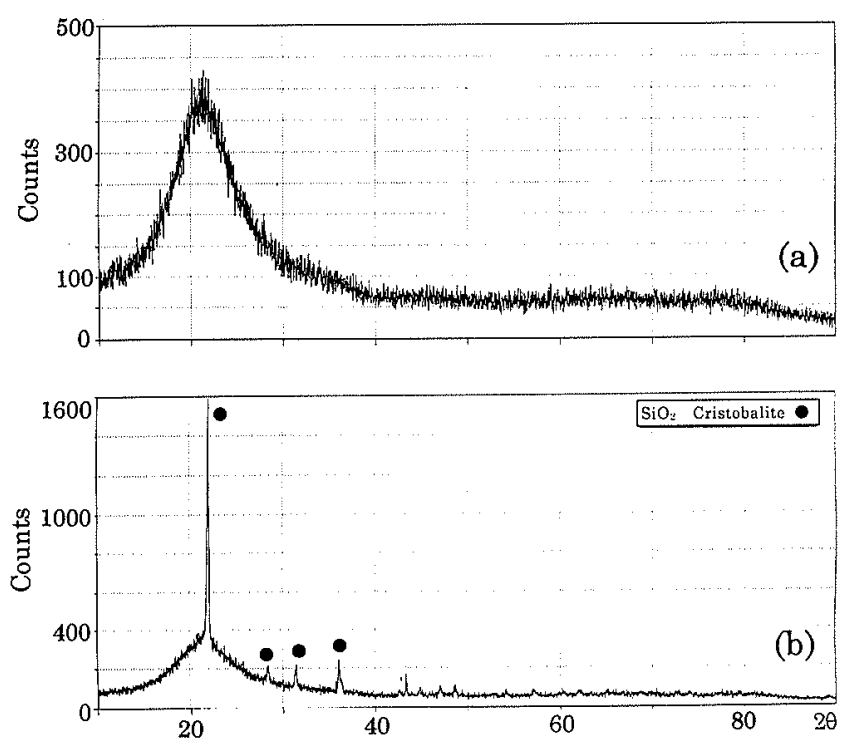

Fig. 2. The X-ray diffraction results of a fused silica crucible (a) before use (b) after use.

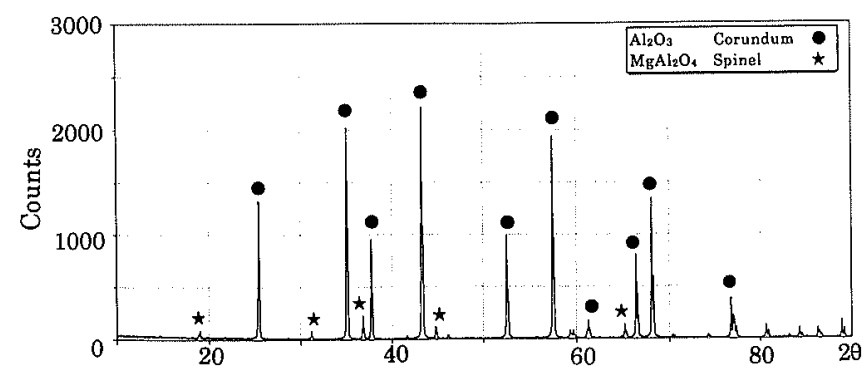

Fig. 3. The $X$-ray diffraction result of an alumina crucible before use.

Figure 2 shows the results of X-ray diffraction on a fused silica crucible before and after the experiment. Figure 2(a) shows that the fused silica crucible used here had a completely amorphous structure before use. Then during heating and cooling, some of the crucible material transformed into a crystalline structure (cristobalite), though most remained amorphous, as Fig. 2(b) shows.

An X-ray diffraction pattern of an alumina crucible is shown in Fig. 3. The crucible material is mainly alumina with small amount of spinel.

\subsection{Effect of Additives}

\subsubsection{Fused Silica Crucible}

Figure 4 shows the effects of the addition of the oxides on the undercooling of molten nickel in a fused silica crucible. The experiments were repeated several times, and the range and average of the undercoolings are presented in this figure. The degree of undercooling in the specimens inoculated with $\mathrm{NiO}$ and $\mathrm{Co}_{3} \mathrm{O}_{4}$ are sim- 


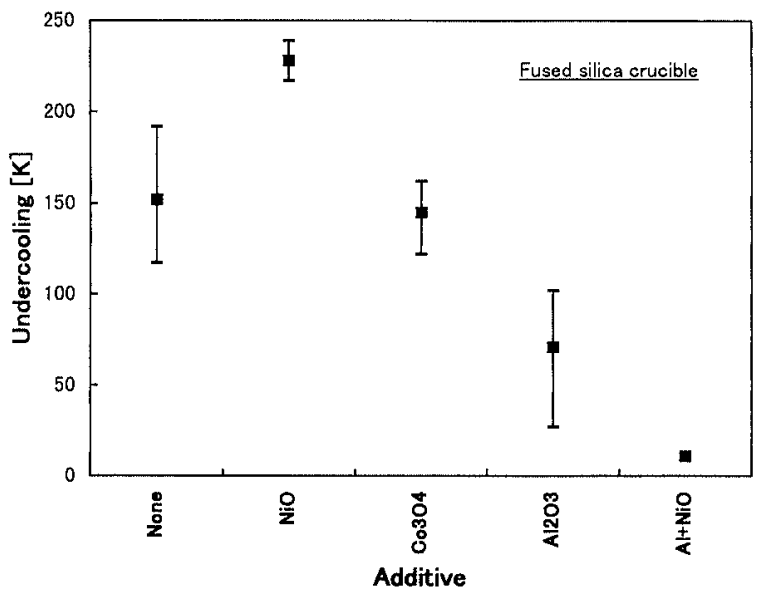

Fig. 4. Average and range of the undercooling measured in the molten nickel inoculated with various additives. Melted and solidified on fused silica crucibles.

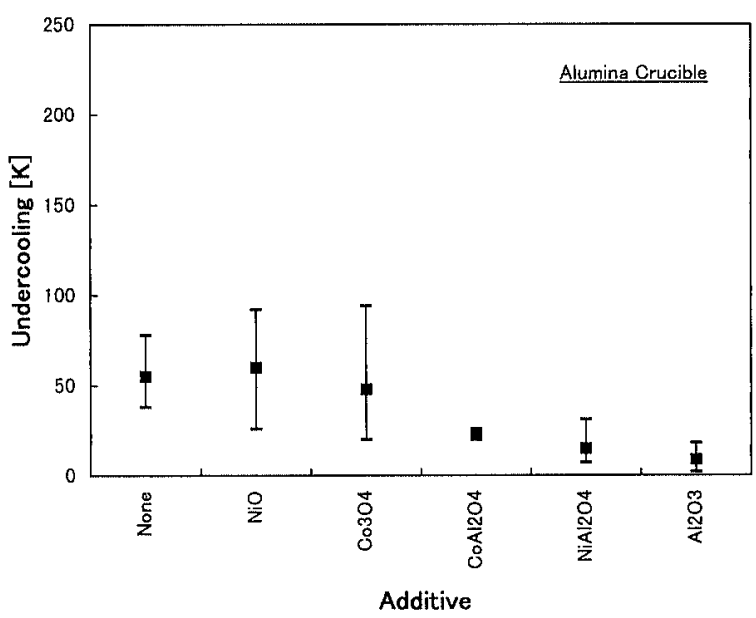

Fig. 5. Average and range of the undercooling measured in the molten nickel inoculated with various additives. Melted and solidified on alumina crucibles.

ilar to that in the specimens without added oxides, so they have scarcely any effect on the undercooling. These oxides did not remain at the bottom of the crucibles. The addition of the alumina powder to the specimens decreased the undercooling. Though some alumina was observed within the specimen, the powder mainly remained at the bottom of crucibles. Therefore, the nickel oxide powder was added to the $\mathrm{Ni}-0.15 \% \mathrm{Al}$ specimens to form alumina directly in the melt; and low undercoolings (9 to $11 \mathrm{~K}$ ) were obtained, as shown in Fig. 4.

\subsubsection{Alumina Crucible}

Figure 5 shows the effects of the oxide additives on the undercooling of molten nickel using an alumina crucible. The specimens inoculated with $\mathrm{NiO}$ and $\mathrm{Co}_{3} \mathrm{O}_{4}$ undercooled to almost the same degree as specimens without addition of oxides. In these runs, the powders were not observed at the bottom of crucibles, and no inclusion of these oxides in the specimens could be detected by XMA.

The lowest undercooling $(2 \mathrm{~K})$ was obtained by adding alumina powder. By taking map analyses with XMA, a few alumina inclusions below $1 \mu \mathrm{m}$ were observed in the specimens with added alumina. Furthermore, it had been

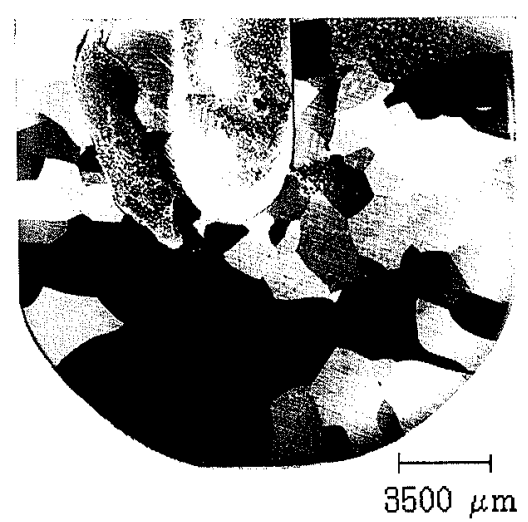

Fig. 6. Grain structure of the specimen solidified in a fused silica crucible without inoculating.

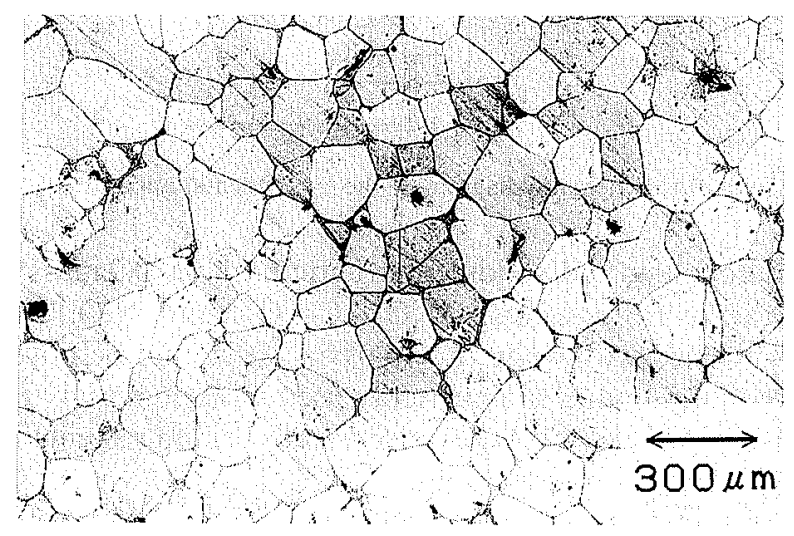

Fig. 7. Microstructure of specimens inoculated with $\mathrm{Co}_{3} \mathrm{O}_{4}$.

reported that a low undercooling, $9 \mathrm{~K}$, was obtained by adding a small quantity of aluminum to the raw material of nickel. ${ }^{4)}$ Of course, alumina inclusions were also formed in that experiment.

\subsection{Grain Structures}

\subsubsection{No Addition of Oxides}

The grains in the specimens solidified in fused silica crucibles were somewhat elongated from the outside towards the center of specimens and were equiaxed in the center. The average size of the elongated and equiaxed grains was estimated about $4000 \mu \mathrm{m}$. The grain structure of a specimen solidified in a fused silica crucible is typically shown in Fig. 6.

In the specimens solidified in alumina crucibles, the structure was composed of a few coarse grains, and the grain size was too coarse relative to the specimen size to be estimated as previously reported. ${ }^{4}$ The structure was much coarser than that in the specimens solidified in a fused silica crucible.

\subsubsection{Addition of Oxides}

The addition of oxide refined the solidified structures of specimens in both fused silica and alumina crucibles. The finest structures were observed in the specimens added with $\mathrm{CO}_{3} \mathrm{O}_{4}$ and $\mathrm{NiO}$. The typical structure of a specimen inoculated with $\mathrm{Co}_{3} \mathrm{O}_{4}$ having $100 \mu \mathrm{m}$ grain size is shown in Fig. 7. The grain size was sometimes as large as about $350 \mu \mathrm{m}$, due to differences in the oxygen contents and undercoolings of the specimens. The grain size of the specimens with added alumina was about 


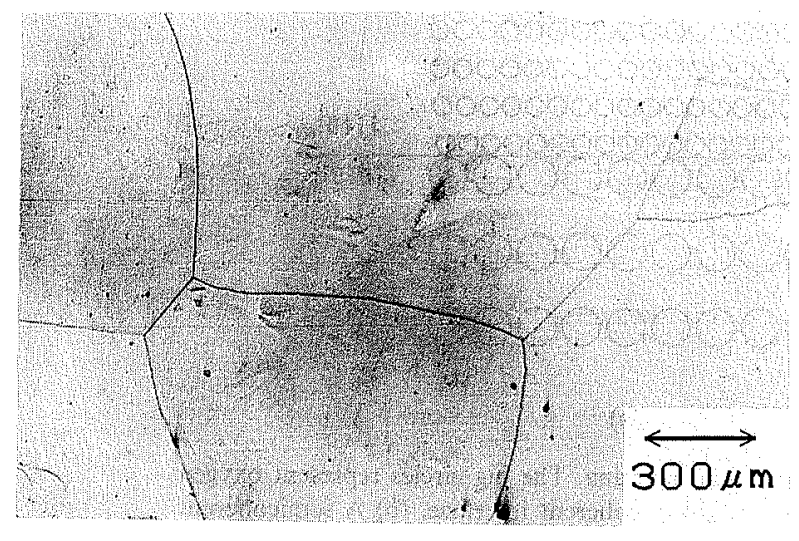

Fig. 8. Microstructure of specimens inoculated with $\mathrm{Al}_{2} \mathrm{O}_{3}$.

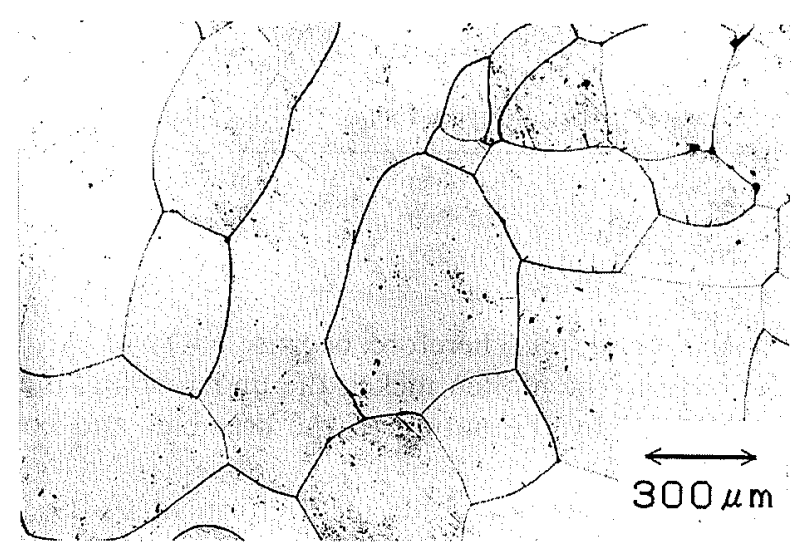

Fig. 9. Microstructure of specimens inoculated with $\mathrm{CoAl}_{2} \mathrm{O}_{4}$.

$1500 \mu \mathrm{m}$ as shown in Fig. 8. The grain size of the specimens inoculated with either $\mathrm{CoAl}_{2} \mathrm{O}_{4}$ or $\mathrm{NiAl}_{2} \mathrm{O}_{4}$ was about $350 \mu \mathrm{m}$ in both cases, as shown in Fig. 9.

\section{Discussion}

\subsection{Crucible Materials}

In the experiments using the fused silica crucible, high undercoolings up to $192 \mathrm{~K}$ were achieved when no oxide powder was added. The other investigators who used fused silica crucibles, ${ }^{16)}$ have also reported high degrees of undercooling up to $270 \mathrm{~K}$ for pure nickel. On the other hand, low degrees of undercooling, on average $55 \mathrm{~K}$, were obtained for specimens solidified in alumina crucibles. Since both alumina and fused silica are stable oxide compounds, their respective crystal structures, i.e. amorphous in fused silica and crystalline in alumina, might explain the diminishing effect of alumina crucible on the undercooling.

The maximum undercoolings for several metals solidified in fused silica or alumina crucibles are summarized in Table 2. The ratios of the degrees of undercooling to the melting points are also listed. It is demonstrated that the non-crystalline crucibles cause high undercoolings in the molten metals and alumina crucibles cause low undercoolings. It is noteworthy that the disregistry between alumina and $\mathrm{Fe}$ is low. ${ }^{21)}$ Undercoolings of about $0.2 T_{\mathrm{m}}$ are expected for homogeneous nucleation in metals, and $0.19 T_{\mathrm{m}}$ has been reported for nickel. ${ }^{22)}$ In this experiment using the fused silica crucible, degrees of
Table 2. Maximum reported undercoolings of several metals in different crucible materials.

\begin{tabular}{llrrrr}
\hline Metal & Crucible & $\Delta T(\mathrm{~K})$ & $T_{\mathrm{m}}(\mathrm{K})$ & $\Delta T / T_{\mathrm{m}}$ & Ref. \\
\hline $\mathrm{Sn}$ & Pyrex & 105 & 505 & $0.2 \mathrm{I}$ & $17)$ \\
$\mathrm{Pb}$ & Pyrex & 80 & 600 & 0.13 & $17)$ \\
$\mathrm{Cu}$ & Silica & 200 & 1356 & 0.15 & $18)$ \\
$\mathrm{Ni}$ & Quartz & 240 & 1726 & 0.14 & $19)$ \\
$\mathrm{Ni}$ & Fused silica & 271 & 1726 & 0.16 & $16)$ \\
$\mathrm{Fe}$ & Alumina & 55 & 1808 & 0.03 & $20)$ \\
\hline
\end{tabular}

undercooling up to $0.11 T_{\mathrm{m}}$ were obtained.

\subsection{Effect of Additives}

\subsection{1. $\mathrm{Al}_{2} \mathrm{O}_{3}$}

The diminishing effect of the added alumina on the undercooling of molten nickel is demonstrated from the undercooling of the alumina-inoculated specimens in both fused silica and alumina crucibles, as shown in Figs. 4 and 5 . In a fused silica crucible, the average undercooling falls from 152 to $71 \mathrm{~K}$ by the addition of alumina powder. It falls from 55 to $9 \mathrm{~K}$ in an alumina crucible.

Although the addition of $\mathrm{NiO}$ to the pure nickel had no effect on undercooling, the addition of $\mathrm{NiO}$ to the $\mathrm{Ni}-0.15 \% \mathrm{Al}$ alloy caused a low undercooling (on average $10 \mathrm{~K}$ ). These results indicate the diminishing effect of alumina inclusions produced in the molten nickel due to the reaction between $\mathrm{NiO}$ and solute aluminum. This is the best evidence to indicate that the alumina is a good heterogeneous nucleation catalyst for molten nickel.

\subsection{2. $\mathrm{NiAl}_{2} \mathrm{O}_{4}$ and $\mathrm{CoAl}_{2} \mathrm{O}_{4}$}

Figure 5 shows that the $\mathrm{CoAl}_{2} \mathrm{O}_{4}$ and $\mathrm{NiAl}_{2} \mathrm{O}_{4}$ additives have diminishing effects on the undercooling of molten nickel using an alumina crucible. These oxides decompose in molten nickel with a low oxygen content, based on thermodynamic concepts. ${ }^{4,23)}$ The products of decomposition of these compounds are soluble oxygen, soluble $\mathrm{Co}$ or $\mathrm{Ni}$, and insoluble alumina. It might be considered that the low undercoolings are caused by the alumina.

\subsection{Heterogeneous Nucleation of Alumina.}

There have been several attempts to relate the characteristics of the heterogeneous nucleation catalyst to its effects on the undercooling. ${ }^{9-11)}$ One is the disregistry theory which postulates that the undercooling due to the addition of a given catalyst would decrease parabolically with the lattice disregistry between catalyst and solidifying nucleus. ${ }^{9)}$ There is much experimental evidence to indicate this relationship. This includes the experimental results for iron which show a simple parabolic relation. ${ }^{20,21)}$ The majority of reported data for gold nucleation reveals a similar relation. ${ }^{24)}$ Correlation between the degree of undercooling and disregistry has also been reported for lead. ${ }^{10)}$ The compounds $\mathrm{TiC}, \mathrm{TiAl}_{3}$, and $\mathrm{TiB}_{2}$, which are produced in molten aluminum by adding commercial grain refiners, ${ }^{1}$ ) have low disregistry values with aluminum $(6.5,4.3$, and $5.9 \%$ respectively). An investigation on the grain refining of $\mathrm{Sn}, \mathrm{Pb}, \mathrm{Zn}, \mathrm{Sb}, \mathrm{Al}$, 


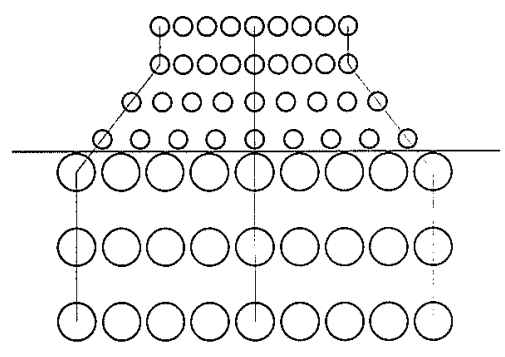

(a)

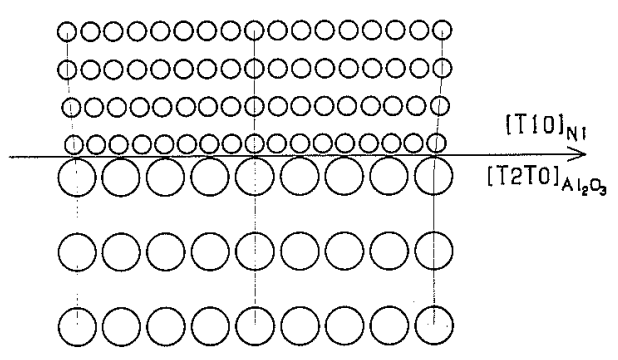

(b)

Fig. 10. Assumed atomic arrangements in the interface of nickel and alumina. The big circles represent oxygen atoms of alumina and small ones represent nickel atoms. (a) A coherent interface. (b) A semicoherent interface.

$\mathrm{Mg}$, and $\mathrm{Cu}$ employing mold washes of various powdered metals and compounds, revealed that powdered metals possessing the same crystal structure as the metal being cast were effective nucleating agents (i.e. produced a grain refinement) when the lattice misfit between two solids was less than $10 \% .{ }^{25}$ )

On the other hand, it was reported for the heterogeneous nucleation of $\mathrm{Sn}$ with various catalysts that the calculated values of disregistry do not correlate with degree of undercooling when the emulsion method is used. ${ }^{2)}$ However there is some evidence that crystal structure has some effects on the undercooling of Sn when the other methods are used. ${ }^{26)}$

Figure 10 schematically shows two assumptions about the atomic matching along the [110] direction of $\mathrm{Ni}$ and the $[\overline{1} 2 \overline{1} 0]$ direction of alumina. Figure $10(\mathrm{a})$ shows a coherent interface where the strain energy is high. Figure 10 (b) shows a semicoherent interface where the strain is low, because the matchless atomic layers of $\mathrm{Ni}$ almost completely accommodate the lattice misfit without any long-range strain field.

If one considers the spacing between the nearest neighbors of nickel atoms, the disregistry between nickel and alumina will be $91 \%$. This value indicates a high strain energy on the interface keeping the interface coherent (Fig. 10(a)). It would then mean that alumina cannot be a heterogeneous nucleation catalyst for nickel, which is contrary to the experimental results. Considering instead the spacing between the next nearest neighbors of nickel atoms, the disregistry falls to $4.5 \%$. This value indicates a low strain energy on the interface where mismatch is mainly taken up by the matchless atomic layers (Fig. 10(b)). That is, the modified planar disregistry can be defined by introducing this defect in the interfacing of the nuclei and the catalyst. This $4.5 \%$ value for disregistry supports the findings that alumina is good heterogeneous nucleation catalyst for nickel.

\subsection{Effect of $\mathrm{NiO}$ and $\mathrm{Co}_{3} \mathrm{O}_{4}$}

\subsubsection{Undercooling}

Addition of $\mathrm{NiO}$ and $\mathrm{Co}_{3} \mathrm{O}_{4}$ barely affects the undercooling, as shown in Figs. 4 and 5, although the disregistries of these oxides with nickel is low, as previously reported. ${ }^{5)}$ The added $\mathrm{NiO}$ must be decomposing into nickel and solute oxygen in the molten $\mathrm{Ni}$, because $\mathrm{NiO}$ is not stable in the molten nickel. $\mathrm{Co}_{3} \mathrm{O}_{4}$ is also soluble
Table 3. Average values of oxygen and cobalt contents, for inoculated specimens.

\begin{tabular}{lcc}
\hline Additive & Oxygen (ppm) & Cobalt (mass\%) \\
\hline None & 30 & - \\
$\mathrm{Co}_{3} \mathrm{O}_{4}$ & 360 & 0.160 \\
$\mathrm{NiO}$ & 255 & - \\
\hline
\end{tabular}

in the molten nickel. Therefore, because $\mathrm{NiO}$ and $\mathrm{Co}_{3} \mathrm{O}_{4}$ are soluble in the molten nickel, the undercooling must be controlled by the nature of the crucibles and concentration.

Cobalt oxide is not stable in the form of $\mathrm{Co}_{3} \mathrm{O}_{4}$ at high temperatures. Over $1190 \mathrm{~K}$ it converts to $\mathrm{CoO}$ in the atmosphere.

$$
\mathrm{Co}_{3} \mathrm{O}_{4}=3 \mathrm{CoO}+1 / 2 \mathrm{O}_{2}
$$

$\mathrm{CoO}$ is stable in the high temperatures up to its melting point (about $2030 \mathrm{~K}$ ). ${ }^{27}$ ) The free energy of decomposition and dissolution of $\mathrm{CoO}$ in molten nickel can be calculated by considering the following reactions:

$$
\begin{gathered}
\mathrm{CoO}=\mathrm{Co}(\mathrm{s})+1 / 2 \mathrm{O}_{2} \\
\Delta G^{\circ}=245600-78.66 T \quad \mathrm{~J} / \mathrm{mol}^{28)} \\
\mathrm{Co}(\mathrm{s})=\mathrm{Co}(\mathrm{l}) \\
\Delta G^{\circ}=16192-9.16 T \quad \mathrm{~J} / \mathrm{mol}^{28)} \\
1 / 2 \mathrm{O}_{2}=[\mathrm{O} \%]_{\mathrm{Ni}} \\
\Delta G^{\circ}=-102420+19.33 T \quad \mathrm{Jg} / \mathrm{at}^{23)}
\end{gathered}
$$

Combination of the above reactions leads to:

$$
\mathrm{CoO}=[\mathrm{Co}]_{\mathrm{Ni}}+[\mathrm{O} \%]_{\mathrm{Ni}} \quad \Delta G^{\circ}=159372-68.49 T
$$

where $[\mathrm{Co}]_{\mathrm{Ni}}$ and $[\mathrm{O}]_{\mathrm{Ni}}$ are the solute cobalt and oxygen in the molten nickel, respectively. At the melting point of nickel, $1726 \mathrm{~K}$, the free energy of Eq. (5) is $41 \mathrm{~kJ} / \mathrm{mol}$. Therefore, the equilibrium constant is 0.057 , i.e. $K=$ $N_{\mathrm{Co}} \% \mathrm{O}=0.057$ where $N_{\mathrm{Co}}$ is atomic fraction of Co in the $\mathrm{Ni}$ and $\% \mathrm{O}$ is the mass percentage of solute oxygen in the nickel. It indicates that in low concentrations of oxygen and cobalt in molten nickel, $\mathrm{CoO}$ decomposes to solute cobalt and oxygen.

In the present work, about $0.2 \% \mathrm{Co}_{3} \mathrm{O}_{4}$ was added to the raw material. If all of the oxide decomposes and dissolves in the molten nickel, the oxygen and cobalt 
contents of the specimen would be 0.059 and $0.16 \%$, respectively, which are quite smaller than the equilibrium values derived from the equilibrium constant of Eq. (5). The actual oxygen content listed in Table 3 is lower than the calculated value because of the escape of oxygen to the atmosphere, but the cobalt content is in agreement with the calculated value. Therefore, based on the thermodynamic concepts, it is to be expected that $\mathrm{Co}_{3} \mathrm{O}_{4}$ partly or completely decomposes in molten nickel and increases the oxygen and cobalt contents of those specimens.

\subsubsection{Grain Structure}

While the added $\mathrm{NiO}$ and $\mathrm{Co}_{3} \mathrm{O}_{4}$ do not affect the undercooling, they have a strong effect on the structures; and the finest structures were observed in these specimens. Throughout these specimens no oxide remained. The refining effect of $\mathrm{NiO}$ and $\mathrm{Co}_{3} \mathrm{O}_{4}$ cannot be explained by the nucleation mechanism.

Table 3 shows the chemical analysis of specimens inoculated with the different powders. The oxygen content of the $\mathrm{NiO}$ and $\mathrm{Co}_{3} \mathrm{O}_{4}$ specimens is higher than that of the specimens without added oxides. It has been reported ${ }^{4,16)}$ that high oxygen content in nickel specimens causes a fine structure. The $\mathrm{NiO}$ and $\mathrm{Co}_{3} \mathrm{O}_{4}$ specimens in this experiment had sufficient oxygen contents. The grain size of these specimens was on the same level ( 90 to $130 \mu \mathrm{m})$ as that of specimens with high oxygen contents. ${ }^{4)}$ Looking at the microstructure, the $\mathrm{Ni}-\mathrm{O}$ eutectic appeared on the grain boundaries (see Fig. 7). Therefore, it can be suggested that the refining effect of $\mathrm{NiO}$ and $\mathrm{CO}_{3} \mathrm{O}_{4}$ is largely due to their effect on the oxygen content of the specimens.

\section{Conclusions}

The effect of crucible materials and oxide additives on the static undercooling and solidified structure of pure nickel were experimentally investigated. Our conclusions can be summarized as follows:

(1) A high undercooling can be obtained by using a fused silica crucible, and a low one by using an alumina crucible.

(2) The addition of alumina profoundly reduces the undercooling of molten nickel.

(3) The crystallographic considerations can explain the effect of alumina on the undercooling.

(4) The addition of $\mathrm{NiO}$ and $\mathrm{CO}_{3} \mathrm{O}_{4}$ can significantly refine the structure of pure nickel, while having barely any effect on undercooling.

(5) A good heterogeneous nucleation catalyst is not necessarily suitable for refining the grain structure.

\section{REFERENCES}

1) P. S. Mohanty, F. H. Samuel, J. E. Gruzleski and T. J. Kosto: Light Metals 1994, TMS, (1994), 1039.

2) J. H. Perepezko and M. Uttormark: ISIJ Int., 35 (1995), 580.

3) W. T. Kim and B. Cantor: Acta Metall. Mater., 42 (1994), 3115.

4) A. Abedi, M. Kudoh and Y. Itoh: ISIJ Int., 35 (1995), No. 6, 589.

5) A. Abedi, M. Kudoh and Y. Itoh: Solidification Science and Processing, TMS, US, (1996), 27

6) D. M. Herlach: Mater. Sci. Eng., R12 (1994), 179

7) J. H. Perepezko and M. J. Uttormark: Metall. Mater. Trans., 27A (1996), 533.

8) D. T. J. Hurle: Handbook of Crystal Growth, Elsevier Science Publishers, North-Holland, (1993), 204.

9) D. Turnbull and R. Vonnegut: Ind. Eng. Chem., 44 (1952), 1292.

10) P. B. Corosley, A. W. Douglas and L. F. Momdolfo: The Solidification of Metals, The Iron and Steel Institute, London, (1968), 10

11) W. A. Tiller and T. Takahashi: Acta Metall., 17 (1969), 483.

12) E. Chang, B. Tseng, J. C. Chou and V. Yin: AFS Trans., 96 (1988), 47

13) R. C. Feagin: U.S. Patent 3259948, (1966).

14) F. Jian and Y. Bin: High Temperature Alloys for Gas Turbine, D. Reidel Publishing Company, Holland, (1982), 987.

15) G. K. Bouse and J. R. Mihalisin: Metallurgy of investment cast superalloy components, Superalloys, Supercomposites and Superceramics, America Press, Inc., (1989), 99.

16) B. L. Jones and G. M. Weston: J. Aust. Inst. Met., 15 (1970), No. 4, 189.

17) B. E. Sundquist and L. F. Mondolfo: Trans. AlME, 227 (1961), 157.

18) B. L. Jones and G. M. Weston: J. Aust. Inst. Met., 15 (1970), 167.

19) J. L. Walker: Physical Chemistry of Process Metallurgy, Part II, Interscience, New York, (1961), 845.

20) B. L. Bramfitt: Metall. Trans., 1 (1970), 1987.

21) T. Ohashi, T. Hiromoto, H. Fujii, Y. Nuri and K. Asano: Tetsu-to-Hagané, 62 (1976), 10.

22) G. J. Davies: Solidification and Casting, Applied Science Publishers Ltd., UK, (1973), 19.

23) A. Majumdar, A. McLean, H. B. Bell and M. Iwase: Can. Metall. Q., 32 (1993), 321

24) G. M. Pound: Liquid Metals and Solidification, ASM, (1958), 87.

25) J. A. Reynolds and C. R. Tottle: J. Inst. Met., 80 (1951), 93.

26) M. E. Glicksman and W. J. Childs: Acta Metall., 10 (1962), 925.

27) E. Aukrust and A. Muan: Trans. AIME, 230 (1964), 378.

28) O. Kubaschewski, C. B. Alcock and P. J. Spencer: Materials Thermochemistry, Pergamon Press Ltd., UK, (1993). 